\title{
COMPLICATED PRESENTATION OF PIERRE ROBIN SYNDROME- A CASE REPORT
}

\author{
P. Gouthami1 ${ }^{1}$ V. Jyothirmayee ${ }^{2}$, Aditya Sai Rama Krishna K. ${ }^{3}$, Sahithi Gurramkonda ${ }^{4}$, Dasari Vijay Sagar ${ }^{5}$
}

${ }_{1}^{1}$ Assistant Professor, Department of Paediatrics, RVM Institute of Medical Sciences and Research Centre, Mulugu Mandal, Siddipet, Telangana, India.

${ }^{2}$ Assistant Professor, Department of Pharmacy Practice, Geethanjali College of Pharmacy, Keesara Mandal, Medchal District., Hyderabad, Telangana, India.

${ }_{3}^{3}$ Pharm-D Intern, RVM Hospital, Laxmakkapally Village, Mulugu Mandal, Siddipet, Telangana, Siddipet, Telangana, India. ${ }^{4}$ Pharm-D IV Year, Geethanjali College of Pharmacy, Cheeryal Village, Keesara Mandal, Medchal District., Hyderabad, Telangana, India. 5Pharm-D Intern, RVM Hospital, Laxmakkapally Village, Mulugu Mandal, Siddipet, Telangana, India.

HOW TO CITE THIS ARTICLE: Gouthami P, Jyothirmayee V, Krishna ASRK, et al. Complicated presentation of pierre robin syndrome- a case report. J. Evolution Med. Dent. Sci. 2019;8(27):2213-2214, DOI: 10.14260/jemds/2019/484

\section{PRESENTATION OF CASE}

A 15-year-old girl student presently a 10th grader from a state high school was diagnosed with Pierre Robin syndrome during the first month of life, thus was informed that she had not been immunised since birth. A detailed history was obtained, which revealed that she had complaints of flattering weight, severe malnutrition and respiratory distress and no history of neuro-developmental delay. Family history: twins were born, the other twin passed away (stillbirth), and no apparent congenital anomalies found.

Thus, past data was found to be that she had a history of halitosis and hearing abnormalities. On subject interrogation, there was no history of recurrent cold or cough, spinal abnormalities, bowel, and bladder dysfunction.

The child was dysmorphic; had lower centiles of her BMI for her age, pallor of skin, retrognathia, crowned teeth, and mandible deformity. Cardiovascular system examination- no murmur. No abnormality was detected on two-dimensional echocardiography. Hence, mandibular osteotomy was done carefully after correction of anaemia by considering all the above conditions. The child improved and got discharged within a week.

\section{CLINICAL DIAGNOSIS}

Pierre Robin Syndrome.

\section{DIFFERENTIAL DIAGNOSIS}

- Stickler syndrome.

- Velocardiofacial syndrome.

- Treacher Collins syndrome.

\section{PATHOLOGICAL DISCUSSION}

Pierre Robin sequence (PRS) presents with the association of micrognathia, glossoptosis, and airway obstruction, this condition occurs at birth, and cannot be acquired in later developmental stages. In 1934 a French physician reported the association with cleft palate and this constellation of findings later termed it as a syndrome.(1)

'Financial or Other Competing Interest': None.

Submission 13-04-2019, Peer Review 22-06-2019,

Acceptance 28-06-2019, Published 08-07-2019.

Corresponding Author:

Aditya Sai Rama Krishna K.,

Pharm-D Intern,

RVM Hospital, Laxmakkapally Village,

Mulugu Mandal, Siddipet,

Telangana-502279, Telangana, India

E-mail: sairamaditya95@gmail.com

DOI: $10.14260 / \mathrm{jemds} / 2019 / 484$
Epidemiological studies reveal that Pierre Robin syndrome is a rare and complex syndrome which has been affecting one in 8,500 to 14,000 births also there is a higher incidence for twins and hence, no gender differences identified. Multiple congenital disabilities have commonly been described, which correlates with inadequate growth of the lower jaw. Also, to help in recovering up weight loss and feeding difficulties, a nasogastric tube for feeding is essential to gain weight.(2)

The Complete Blood Picture of the child revealed $\mathrm{Hb}-10.3$ gms \%, which confirms anaemia and Ionised Calcium- 1.11 mmol/L, which significantly shows a lower level of calcium. Also, the child developed the complication of TMJ Ankylosis right side, which is further corrected by osteotomy operative procedure. Since a long time ago, she had feeding difficulties, which is very common in patients presenting with PRS. Hence this reflected with her compromised immunity; thereby, it can be corrected by a surgical procedure. Mandibular Osteotomy procedure executed, which shows mandible correction is done to widen the Jaw space. (Fig. 1) The lateral view displays the rods positioned post-surgery. (Fig. 2)

PRS patients will be barred from the mandibular distraction when they present with other anomalies such as central apnoea, neurologic compromise, multilevel airway obstruction, or airway oedema from severe reflux. In patients who are not qualified for mandibular distraction, a tracheostomy is done in the neonatal period. Some patients may later resolve their abnormalities and then be offered a mandibular distraction to facilitate decannulation.(3)

Two PRS cases that developed severe upper airway obstruction immediately after birth and were rescued by fiberoptic nasotracheal intubation.(4) Numerous theories have been explained this syndrome among them; the mechanical theory is most popular. This theory considers the impact of various external factors on the fetus in the intrauterine period. Furthermore, the mechanical theory gets accomplished by the neurological theory and the genetic theory. Hence the neurological theory refers to delay in nerve maturation which is observed in the electromyography from the tip of the tongue. Finally, the genetic theory suggests the fact that this syndrome might be associated with chromosomal deletions. Among the various medical problems encountered the utmost important ones in this syndrome remain breathing difficulties, (Dyspnoea) and eating disorders.(5)

Pierre Robin sequence (PRS) is a congenital abnormality which is characterised by the presence of a combination of 
mandibular hypoplasia, glossoptosis and often Labio-palatin clefts which is the most common type of craniofacial malformation encountered in practice and also among most common congenital abnormalities. PRS is a nonspecific anomalad which may occur either as an isolated defect or as a broader group of malformations. The word "sequence" suggests that one anomaly leads to subsequent abnormalities, and micrognathia is considered to be the inciting anomaly in patients with PRS.

The anatomic changes in PRS are essential; hence, the method needs to be with a radical understanding of the anatomic foundation of the sequence. The mandible is the first pharyngeal arch which is formed from primordium through migrating the neural crest cells which appear in the duration of the fourth week of gestation. At six weeks of being pregnant, the trigeminal nerve stimulates endochondral osteogenesis from the Meckel cartilage, forming structures of the mandible. When the genetic syndromes or deformational factors disrupt fetal growth, thus results in micrognathia and causes retro positioning of the tongue. If the above process occurs before the eighth week of pregnancy, then closure of palatal shelves is being prevented, resulting in the formation of a U-shaped cleft palate. $(3,4)$

In general, the notion of distraction begins with an osteotomy followed by a linear mechanical force from the distraction device, which assists in directing through the formation of bone. In Pierre Robin Sequence the Surgical Considerations include the mineralisation and inurement of new bone formed by the distraction procedure, thereby time of full consolidation may vary but is usually between 6 to 12 weeks following completion of distraction.(6)

Moreover, the Girl child could be prone to possible risks such as irregular menstruation, malnutrition and chances of infections due to low immunity where the reasonable care and management is necessary.(7)

\section{FINAL DIAGNOSIS}

Delayed Presentation of Pierre Robin Syndrome.

All PRS cases should be thoroughly investigated to diagnose and formulate management. Our case of a 15-yearold child, which displayed a unique presentation of Pierre Robin sequence underwent surgical Correction procedure. Similarly, each case needs to be assessed clearly. Hence it is the responsibility of physicians and pharmacists to recognise.

the disorder in time to provide the follow-up, therapy, and counselling

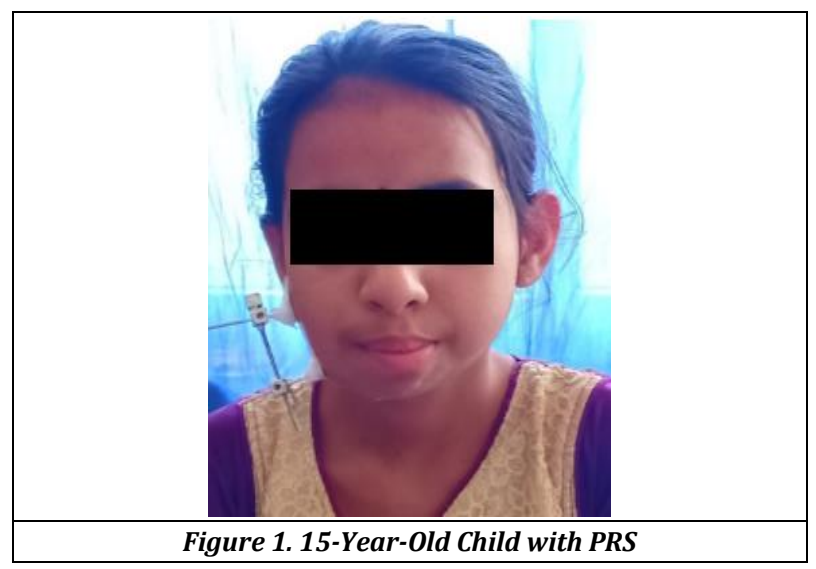

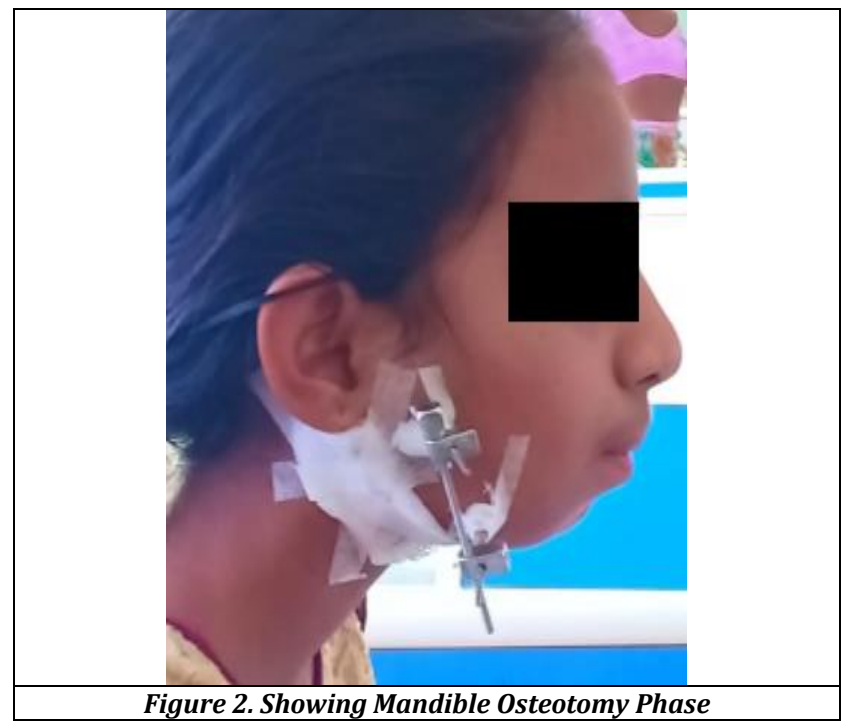

\section{REFERENCES}

[1] Gupta R, Patel M, Bajaj N. Pierre Robin syndrome: a case report. Int J Res Med Sci 2015;3(11):3432-4.

[2] Maria A, Haţegan CB, Talaş D. Pierre-Robin syndrome: a Romanian psycho-pedagogical case report. Procedia - Social and Behavioral Sciences 2013;78:245-9.

[3] Lee JC, Bradley JP. Surgical considerations in Pierre Robin sequence. Clin Plast Surg 2014;41(2):211-7.

[4] Hegde RJ, Mathrawala NR. Pierre Robin sequence: report of two cases. J Indian Soc Pedod Prev Dent 2010;28(4):326-30.

[5] Takeshita S, Ueda H, Goto T, et al. Case report of Pierre Robin sequence with severe upper airway obstruction which was rescued by fiberoptic nasotracheal intubation. BMC Anesthesiol 2017;17(1):43.

[6] Côté A, Fanous A, Almajed A, et al. Pierre Robin sequence - review of diagnostic and treatment challenges. Int J Pediatr Otorhinolaryngol 2015;79(4):451-64.

[7] Fariña R, Castellón L, Nagelash E, et al. A new way to anchor the external device in mandibular distraction: three case reports with a Pierre Robin sequence. Int J Oral Maxillofac Surg 2011;40(5):471-4. 